\title{
Editorial
}

\section{Natural Compounds: A Dynamic Field of Applications}

\author{
Ana M. L. Seca ${ }^{1,2, *(1)}$ and Laila Moujir ${ }^{3}$ \\ 1 cE3c-Centre for Ecology, Evolution and Environmental Changes/Azorean Biodiversity Group \& Faculty of \\ Sciences and Technology, University of Azores, Rua Mãe de Deus, 9500-321 Ponta Delgada, Portugal \\ 2 LAQV-REQUIMTE, University of Aveiro, 3810-193 Aveiro, Portugal \\ 3 Department of Biochemistry, Microbiology, Genetics and Cell Biology, Facultad de Farmacia, Universidad de \\ La Laguna, 38206 San Cristóbal de La Laguna, Spain; lmoujir@ull.es \\ * Correspondence: ana.ml.seca@uac.pt; Tel.: +351-29-6650174
}

Received: 2 June 2020; Accepted: 7 June 2020; Published: 10 June 2020

check for updates

\begin{abstract}
Nature represents an amazing source of inspiration since it produces a great diversity of natural compounds selected by evolution, which exhibit multiple biological activities and applications. A large and very active research field is dedicated to identifying biosynthesized compounds, to improve/develop new methodologies to produce/reuse natural compounds and to assess their potential for pharmaceutical, cosmetic and food industries, among others, and also to understand their mechanism of action. Here, the main results presented in each work are highlighted. The applications suggested are mostly related to pharmacological uses and involve mainly pure natural compounds and essential oils. These works are significant contributions and reinforce the dynamic field of natural products applications.
\end{abstract}

Keywords: natural compounds; therapeutic applications; essential oils; antimicrobial; antitumor; SAR

\section{Introduction}

The compounds produced by nature exhibit a great diversity of chemical structures as a result of the long, selective and evolutive process of species [1], and they constitute the active principles of natural products which have always contributed, a lot, to improve human living conditions [2]. As natural products have widespread uses in traditional medicine [3-5], and a wide range of biological effects demonstrated scientifically, they possess high scientific and industrial value [6-9].

The properties demonstrated by natural compounds constantly encourage scientific research in aspects that lead to significant advances in the identification of new natural compounds, evaluation of the biological activity displayed, understanding of how they cause a biological effect, in the development of new applications and in all cases with beneficial results for humanity.

Despite very significant advances in medicine, many diseases such as cancer, infections, diabetes and cardiovascular diseases remain without affordable, effective and safe therapy. Due to this, the most frequently explored area with relevant results is the development of new drugs from natural sources [7,8,10-14], with natural product-based new drugs being 51\% of small molecules approved and launched in the market between 1981 and 2014 [15].

The demand for natural antimicrobial agents and anticancer drugs is a very active research point [16-20] since cancer and infectious diseases are a significant cause of mortality worldwide [21]. Moreover, the World Health Organization predicts that the incidence of cancer will continue to rise to over 11 million in 2030 [22]. More than 1700 clinical trials involving the natural vinca alkaloids to treat cancer are registered currently on the clinicaltrials.gov platform [23]. Furthermore, the resistance and 
undesirable side effects of antibiotics and antineoplastic agents used in the clinic [24,25] have become pressing problems, leading to a continuous search for new inhibitors with new mechanisms of action.

The application of natural compounds as antioxidant agents is also a hot topic [26-29], once several diseases are, at least partially, a result of free radicals' imbalance [26,30,31]. Overproduction of oxygen free radicals, when associated with the deficiency in antioxidant repair or defence mechanisms, will cause oxidative damage leading to disease development like cancer, inflammation, diabetes, cardiovascular and aging-associated diseases [26,30-32].

Natural products are also applied as an ingredient in cosmetic preparations $[33,34]$ and in the food industry since they exhibit useful preservative properties [35,36].

The limited availability of a natural product is a difficulty when it is a promising molecule for an application. Thus, recently, it has been proposed that several techniques that can improve the natural product yield. It is the case of metabolomics, enable the rapid identification of novel compounds in complex mixtures of natural products, metabolic engineering of cells endowed with the ability of overproduction of new products and metagenomics exploring novel metabolites from microorganisms present in several environments but which remain recalcitrant to culturing [37-39].

Natural compounds are privileged structures because of their structural diversity and multiple biological activities. They are undoubtedly the ideal compounds for the rational design of new drugs and the development of new chemical entities with therapeutic potential $[8,14]$. Thus, research on natural compounds is necessary and very welcome.

This Special Issue is dedicated to present the most recent results about the development of natural compounds applications. Ten original research works, organized by applications, and two reviews are included in this Special Issue. Each of them contributes to the knowledge advance, insofar as they present new applications for known products, new methodologies to obtain new products or the evaluation of a given application, with the applications related to health promotion being the most frequently considered.

\section{Contributions}

Several original papers included in this Special Issue involve the search for new antibacterial and antifungal agents, mainly from secondary metabolites, their derivatives and essential oils of different plant species. Essential oils are a mixture of volatile compounds, mainly mono-, di- and sesquiterpenes, with high commercial value and a wide range of applications $[19,40]$.

Piper caldense (Piperaceae family) is popularly used for the treatment of snakebites, stomach problems and as a sedative [41]. The research presented by Bezerra et al. [42] shows that essential oils from P. caldense leaf are composed, in major proportions, by sesquiterpenes such as caryophyllene oxide, spathulenol, $\gamma$-cadinene and bicyclogermacrene. Although the essential oils do not show antifungal activity against Candida albicans, they exhibit a synergistic effect with the antifungal fuconazole, which increase their activity when used combined. This modulator effect is not observed at the highest concentration. The ability of essential oils to cause complete inhibition of the hyphae prolongation was also demonstrated, being an effect superior to fuconazole [42], which suggests their application as an adjuvant in antimicrobial formulations.

Helianthus annus (Asteraceae, sunflower) has been used as a traditional medicine to treat a variety of ailments, such as rattlesnake, spider, snake and scorpion bites, fevers [43,44], food poisoning [45], burning sensation in the vagina and worms in the ears [46]. Lawson et al. [47] report the chemical composition and antifungal activity of essential oils from the aerial parts of two cultivars of $H$. annuus, "Chianti" and "Mammoth", and wild-growing Helianthus strumosus. Analysis of these essential oils shows they are qualitatively similar and dominated by monoterpenes, in particular sabinene, $\alpha$-pinene, $\beta$-pinene and limonene. The antifungal activity of essential oils and their main constituents were evaluated against three opportunistic pathogenic fungal species, Aspergillus niger, Candida albicans and Cryptococcus neoformans, which mainly affect immunocompromised patients. The essential oils of $H$. 
annus "Chianti" and H. strumosus are the most active against C. neoformans and the authors consider that the activity is due to both enantiomers of pinene.

Carvacrol is a usual essential oils constituent, that exhibits activity against Penicillium digitatum, a citrus crop fungal which causes significant economic losses [48], but whose mechanism of action is not completely clarified. Using an innovative approach, metabolomics based on ${ }^{1} \mathrm{H}-\mathrm{NMR}$ analysis, Wan et al. [49] determine the changes introduced into the P. digitatum metabolism and its energetic balance when this fungus is treated with carvacrol. The results show this compound induces ROS production on P. digitatum, which mainly disturbs the energy production by a decrease in glycolysis followed by an augmentation in gluconeogenesis involving mainly alanine, aspartate and glutamate metabolism.

Phenolic nor-triterpene are described in the literature as antibacterial agents against Gram-positive bacteria [50-52]. Moujir et al. [53] report the antimicrobial activity of five natural phenolic nor-triterpenes, isolated from Maytenus blepharodes and Maytenus canariensis, and four pristimerin derivatives synthesized. The most active compound was the derivative $6 \alpha$-hydroxy-2,3-diacetoxy-pristimerol which is more active than the positive control cephotaxime against spore-forming bacteria and Staphylococcus epidermidis. A comprehensive structure/activity relationship (SAR) study was performed with the aim of the rational design of antimicrobial agents based on the phenolic nor-triterpene scaffold.

In addition to an application as antimicrobials, natural compounds, in pure form or as a mixture like essential oils, are also investigated as therapeutic agents with a potential application on other health problems like aging-associated diseases, cancer, diabetes or wounds.

Portulaca oleracea is used to alleviate a wide range of illnesses [54] and the extracts of this plant are known to possess a strong in vivo antioxidant capacity $[55,56]$. Based on the potent antioxidant activity of natural compounds oleracones isolated from this plant, Yoon et al. [57] carried out the synthesis of oleracones D-F and evaluated their lifespan extension properties using the nematode Caenorhabditis elegans as the experimental aging model. The oleracone $\mathrm{E}$ was the most active to extend the lifespan of nematodes. Therefore, this compound should be considered in the development of anti-aging formulations.

Another study where the antioxidant activity of natural compounds was assessed is proposed by Tungmunnithum et al. [58]. They optimize and validate a new green and fast microextraction procedure to obtain a phenolic acids-rich fraction from almond (Prunus dulcis) cold-pressed oil residue. The authors identified and quantified some of the most abundant constituents, protocatechuic, $p$-hydroxybenzoic, chlorogenic and $p$-coumaric acids and evaluated the antioxidant activity of this fraction. They suggest it as a source of antioxidant natural compounds with applications in food preservation, as medicine and in cosmetic preparations. Thus, it is given a contribution to value a very abundant by-product of the almond oil industry.

Salvia miltiorrhizae is one of the well-known traditional herbal medicines that has increased its scientific interest for its remarkable bioactivity against cardiovascular disease, renal damage, tumor angiogenesis and tumor cell invasion [59,60]. Kang et al. [61] evaluate a series of compounds isolated from S. miltiorrhizae Radix such as tanshinone IIA, rosmarinic acid, salvianic acid A, salvianolic acid B and caffeic acid for their cytotoxic activity and mode of action against the HCT-116 cell line (human colorectal cancer, one of the most commonly diagnosed malignant diseases [62]). Only a terpenoid, tanshinone IIA, shows an inhibitory effect on cell survival $\left(\mathrm{IC}_{50} 61.6 \mu \mathrm{g} / \mathrm{mL}\right)$. Morphological changes observed by Hoechst staining, an increase in cleaved caspase-7 and -8 and Bax expression as well as a decrease in Bcl-2 show this compound as an inducer of apoptosis which may be a useful chemotherapy strategy for patients with colorectal cancer.

The flavonoid-type compounds named chalcones and flavanones are natural isomeric compounds which exhibit a broad range of patented therapeutic applications [63]. Since they are chemically very labile, chalcones and flavanones are also excellent scaffolds to medicinal chemistry and development of new drugs [64-66]. In this context, the optimization of the aldol condensation synthesis route 
by using unexplored bases to prepare hydroxylated and methoxylated chalcones and flavanones proposed by Rosa et al. [67] is well come. The application of the synthesized compounds as cytotoxic, antioxidant, antibacterial and anticholinesterase agents were evaluated, and SAR are discussed. The SAR study showed the same substituent group can cause an opposite effect on the level of different biological activities, given as a significant contribution to better understand the medicinal chemistry of these compounds.

Plants are also considered to be sources of natural compounds with antidiabetic activity, as shown by Numonov et al. [68]. They studied the chemical composition of essential oils from Prangos pabularia roots and describe it as a potent protein tyrosine phosphatase 1B (PTP-1B) inhibitor. Additionally, the authors used docking studies and experimental procedures to indicate coumarin osthole, one of the most abundant constituents, as probably responsible for the potent PTP-1B inhibition, a stronger effect than the positive control, and thus support the use of P. pabularia roots' essential oil and osthole as antidiabetic agents.

Propolis and honey are valuable natural products with several health applications already described in the literature $[69,70]$. However, the properties and chemical composition of these natural products significantly depend on several factors such as the plant species used in their production [71]. Using different samples of Portuguese honey, propolis and a mixture of both, Afonso et al. [72] present an original study where the antioxidant, anti-inflammatory and wound-healing activities of ethanolic extracts of these samples were evaluated. The study demonstrates that propolis extracts have higher phenolic compounds and flavonoid contents than honey extracts. On the other hand, the mixtures of honey/propolis exhibit, in general, a significant wound-healing effect, but the propolis extract 2 (propolis from the red-honey box) is the most active sample, this activity being related to its high antioxidant and anti-inflammatory effect.

The Special Issue also includes two review articles where the applications of natural sesquiterpene lactones and rosmarinic acid as potential medicines are reviewed.

Moujir et al. [73] highlight ten natural sesquiterpene lactones, alantolactone, arglabin, costunolide, cynaropicrin, helenalin, inuviscolide, lactucin, parthenolide, thapsigargin and tomentosin, critically discussing the results of in vivo studies and clinical trials involving these compounds. The work demonstrates the enormous potential of these compounds in the development of new drugs especially for the treatment of oncological and inflammatory diseases. Their application as antifungal, antitrypanosomal and analgesic agents is also discussed, although the most surprising results are related to their sensitizing effect to the action of some clinical drugs, which means their application in combination therapy. Some synthetic derivatives of these sesquiterpene lactones are also highlighted, mainly because they demonstrate very significant improvements in pharmacokinetics and selectivity, compared with the original compounds.

In its turn, Nadeem et al. review the therapeutic value of rosmarinic acid [74]. This natural phenolic compound, very abundant on several edible species such as Rosmarinus officinalis, Ocimum tenuiflorum and Thymus mastichina, exhibits a wide range of biological effects. The authors [74] present and discuss scientific evidence of its antitumor, anti-inflammatory, antimicrobial, antidiabetic, antioxidant, anti-aging, cardio and nephroprotective effects. Further, the mechanism of action is discussed, although the authors identified this aspect as the knowledge gap that needs further investigation.

This Applied Sciences Special Issue emphasizes natural compounds' potential for distinct applications. The authors, from all over the world, contribute with valuable manuscripts to this Special Issue, strengthening the high value of natural compounds and the dynamism of this research field.

Author Contributions: A.M.L.S. and L.M. conceived, designed and wrote the editorial. All authors have read and agreed to the published version of the manuscript.

Funding: This research was funded by FCT-Fundação para a Ciência e a Tecnologia, the European Union, QREN, FEDER, COMPETE, by funding the cE3c centre (UIDB/00329/2020) and the LAQV-REQUIMTE (UIDB/50006/2020) research units, and by the Spanish Ministry Science and Research (MINECO RTI2018-094356-B-C21).

Acknowledgments: Thanks are due to the University of Azores and University of La Laguna. 
Conflicts of Interest: The authors L.M. and A.M.L.S. declare no conflict of interest.

\section{References}

1. Kroymann, J. Natural diversity and adaptation in plant secondary metabolism. Curr. Opin. Plant Biol. 2011, 14, 246-251. [CrossRef] [PubMed]

2. World Health Organization. WHO Traditional Medicine Strategy: 2014-2023; WHO Press: Geneva, Switzerland, 2013; ISBN 978.

3. Yuan, H.; Ma, Q.; Ye, L.; Piao, G. The traditional medicine and modern medicine from natural products. Molecules 2016, 21, 559. [CrossRef] [PubMed]

4. Mukherjee, P.K.; Harwansh, R.K.; Bahadur, S.; Banerjee, S.; Kar, A.; Chanda, J.; Biswas, S.; Ahmmed, S.M.; Katiyar, C.K. Development of Ayurveda-Tradition to trend. J. Ethnopharmacol. 2017, 197, 10-24. [CrossRef] [PubMed]

5. World Health Organization. WHO Global Report on Traditional and Complementary Medicine 2019; WHO Press: Geneva, Switzerland, 2019; Available online: https://www.who.int/traditional-complementary-integrativemedicine/WhoGlobalReportOnTraditionalAndComplementaryMedicine2019.pdf?ua=1 (accessed on 2 June 2020).

6. Martins, A.; Vieira, H.; Gaspar, H.; Santos, S. Marketed marine natural products in the pharmaceutical and cosmeceutical industries: Tips for success. Mar. Drugs. 2014, 12, 1066-1101. [CrossRef] [PubMed]

7. Mushtaq, S.; Abbasi, B.H.; Uzair, B.; Abbasi, R. Natural products as reservoirs of novel therapeutic agents. EXCLI J. 2018, 17, 420-451. [CrossRef] [PubMed]

8. Lautié, E.; Russo, O.; Ducrot, P.; Boutin, J.A. Unraveling plant natural chemical diversity for drug discovery purposes. Front. Pharmacol. 2020, 11, 397. [CrossRef] [PubMed]

9. Sorokina, M.; Steinbeck, C. Review on natural products databases: Where to find data in 2020. J. Cheminform 2020, 12, 20. [CrossRef]

10. Dias, D.A.; Urban, S.; Roessner, U. A historical overview of natural products in drug discovery. Metabolites 2012, 2, 303-336. [CrossRef] [PubMed]

11. Newman, D.J.; Cragg, G.M. Natural products as sources of new drugs over the 30 years from 1981 to 2010. J. Nat. Prod. 2012, 75, 311-335. [CrossRef] [PubMed]

12. Butler, M.S.; Robertson, A.A.B.; Cooper, M.A. Natural product and natural product derived drugs in clinical trials. Nat. Prod. Rep. 2014, 31, 1612-1661. [CrossRef] [PubMed]

13. Thomford, N.E.; Senthebane, D.A.; Rowe, A.; Munro, D.; Seele, P.; Maroyi, A.; Dzobo, K. Natural products for drug discovery in the 21st century: Innovations for novel drug discovery. Int. J. Mol. Sci. 2018, 19, 1578. [CrossRef] [PubMed]

14. Dutta, S.; Mahalanobish, S.; Saha, S.; Ghosh, S.; Sil, P.C. Natural products: An upcoming therapeutic approach to cancer. Food Chem. Toxicol. 2019, 128, 240-255. [CrossRef] [PubMed]

15. Newman, D.J.; Cragg, G.M. Natural products as sources of new drugs from 1981 to 2014. J. Nat. Prod. 2016, 79, 629-661. [CrossRef] [PubMed]

16. Rocha, D.H.A.; Seca, A.M.L.; Pinto, D.C.G.A. Seaweed secondary metabolites in vitro and in vivo anticancer activity. Mar. Drugs 2018, 16, 410. [CrossRef] [PubMed]

17. Seca, A.M.L.; Pinto, D.C.G.A. Plant secondary metabolites as anticancer agents: Successes in clinical trials and therapeutic application. Int. J. Mol. Sci. 2018, 19, 263. [CrossRef]

18. Vengurlekar, S.; Sharma, R.; Trivedi, P. Efficacy of some natural compounds as antifungal agents. Pharmacogn. Rev. 2012, 6, 91-99. [CrossRef] [PubMed]

19. D'agostino, M.; Tesse, N.; Frippiat, J.P.; Machouart, M.; Debourgogne, A. Essential oils and their natural active compounds presenting antifungal properties. Molecules 2019, 24, 3713. [CrossRef] [PubMed]

20. Ribeiro da Cunha, B.; Fonseca, L.P.; Calado, C.R.C. Antibiotic discovery: Where have we come from, where do we go? Antibiotics 2019, 8, 45. [CrossRef] [PubMed]

21. Ritchie, H.; Roser, M. Causes of Death. Published online at OurWorldInData.org. Available online: https://ourworldindata.org/causes-of-death (accessed on 2 June 2020).

22. WHO Website. Available online: https://www.who.int/cancer/resources/keyfacts/en/ (accessed on 29 May 2020). 
23. ClinicalTrials.gov Website. Search Terms: "Vincristine OR Vinblastine OR Vinorelbine OR Vindesine". Available online: https://clinicaltrials.gov/ct2/results?cond=\&term=vincristine+OR+vinblastine+OR+ vinorelbine + OR + vindesine \&cntry $=\&$ state $=\&$ city $=\&$ dist $=($ accessed on 29 May 2020).

24. Laws, M.; Shaaban, A.; Rahman, K.M. Antibiotic resistance breakers: Current approaches and future directions. FEMS Microbiol. Rev. 2019, 43, 490-516. [CrossRef]

25. Chatterjee, N.; Bivona, T.G. Polytherapy and targeted cancer drug resistance. Trends Cancer 2019, 5, $170-182$. [CrossRef] [PubMed]

26. Forni, C.; Facchiano, F.; Bartoli, M.; Pieretti, S.; Facchiano, A.; D’Arcangelo, D.; Norelli, S.; Valle, G.; Nisini, R.; Beninati, S.; et al. Beneficial role of phytochemicals on oxidative stress and age-related diseases. Biomed. Res. Int. 2019, 2019, 8748253. [CrossRef] [PubMed]

27. Pohl, F.; Lin, P.K.T. The potential use of plant natural products and plant extracts with antioxidant properties for the prevention/treatment of neurodegenerative diseases: In vitro, in vivo and clinical trials. Molecules 2018, 23, 3283. [CrossRef] [PubMed]

28. Tavares, W.R.; Seca, A.M.L. Inula L. secondary metabolites against oxidative stress-related human diseases. Antioxidants 2019, 8, e122. [CrossRef]

29. Cardoso, S.M. Special Issue: The antioxidant capacities of natural products. Molecules 2019, 24, 492. [CrossRef] [PubMed]

30. Liguori, I.; Russo, G.; Curcio, F.; Bulli, G.; Aran, L.; Della-Morte, D.; Gargiulo, G.; Testa, G.; Cacciatore, F.; Bonaduce, D.; et al. Oxidative stress, aging, and diseases. Clin. Interv. Aging 2018, 13, 757-772. [CrossRef] [PubMed]

31. Nandita, H.; Manohar, M.; Gowda, D.V. Recent review on oxidative stress, cellular senescence and age-associated diseases. Int. J. Res. Pharma. Sci. 2020, 11, 1331-1342. [CrossRef]

32. Khanna, R.D.; Karki, K.; Pande, D.; Negi, R.; Khanna, R.S. Inflammation, free radical damage, oxidative stress and cancer. Interdiscip. J. Microinflamm. 2014, 1, 109. [CrossRef]

33. Mahesh, S.K.; Fathima, J.; Veena, V.G. Cosmetic potential of natural products: Industrial applications. In Natural bio-Active Compounds; Vol. 2: Chemistry, Pharmacology and Health Care Practices; Swamy, M.K., Akhtar, M.S., Eds.; Springer: Singapore, 2019; pp. 215-250. [CrossRef]

34. Salehi, B.; Sharifi-Rad, J.; Seca, A.M.L.; Pinto, D.C.G.A.; Michalak, I.; Trincone, A.; Mishra, A.P.; Nigam, M.; Zam, W.; Martins, N. Current trends on seaweeds: Looking at chemical composition, phytopharmacology, and cosmetic applications. Molecules 2019, 24, 4182. [CrossRef] [PubMed]

35. Faustino, M.; Veiga, M.; Sousa, P.; Costa, E.M.; Silva, S.; Pintado, M. Agro-food byproducts as a new source of natural food additives. Molecules 2019, 24, 1056. [CrossRef] [PubMed]

36. Baptista, R.C.; Horita, C.N.; Sant'Ana, A.S. Natural products with preservative properties for enhancing the microbiological safety and extending the shelf-life of seafood: A review. Food Res. Int. 2020, 127, 108762. [CrossRef] [PubMed]

37. Trindade, M.; van Zyl, L.J.; Navarro-Fernández, J.; Abd Elrazak, A. Targeted metagenomics as a tool to tap into marine natural product diversity for the discovery and production of drug candidates. Front Microbiol. 2015, 6, 890. [CrossRef] [PubMed]

38. Zhao, Q.; Zhang, J.; Li, F. Application of metabolomics in the study of natural products. Nat. Prod. Bioprospect. 2018, 8, 321-334. [CrossRef] [PubMed]

39. Chen, R.; Yang, S.; Zhang, L.; Zhou, Y.J. Advanced strategies for production of natural products in yeast. iScience 2020, 23, 100879. [CrossRef] [PubMed]

40. Aguilar-Veloz, L.M.; Calderón-Santoyo, M.; González, Y.V.; Ragazzo-Sánchez, J.A. Application of essential oils and polyphenols as natural antimicrobial agents in postharvest treatments: Advances and challenges. Food Sci. Nutr. 2020. [CrossRef]

41. Cardozo-Junior, E.L.; Chaves, M.C.O. Caldensin, a new natural n-methylaristolactam from Piper Caldense. Pharm. Biol. 2003, 41, 216-218. [CrossRef]

42. Bezerra, J.W.A.; Rodrigues, F.C.; Pereira da Cruz, R.; Silva, L.E.; do Amaral, W.; Andrade Rebelo, R.; Begnini, I.M.; Fonseca Bezerra, C.; Iriti, M.; Varoni, E.M.; et al. Antibiotic potential and chemical composition of the essential oil of Piper caldense C. DC. (Piperaceae). Appl. Sci. 2020, 10, 631. [CrossRef]

43. Moerman, D.E. Native American Ethnobotany; Timber Press, Inc.: Portland, OR, USA, 1998.

44. Camazine, S.; Bye, R.A. A study of the medical ethnobotany of the Zuni Indians of New Mexico. J. Ethnopharmacol. 1980, 2, 365-388. [CrossRef] 
45. Mesfin, F.; Demissew, S.; Teklehaymanot, T. An ethnobotanical study of medicinal plants in Wonago Woreda, SNNPR, Ethiopia. J. Ethnobiol. Ethnomed. 2009, 5, 28. [CrossRef] [PubMed]

46. Rahman, A.H.M.M. Medico-ethnobotany: A study on the tribal people of Rajshahi division, Bangladesh. Peak J. Med. Plant Res. 2016, 1, 1-8.

47. Lawson, S.K.; Sharp, L.G.; Powers, C.N.; McFeeters, R.L.; Satyal, P.; Setzer, W.N. Essential oil compositions and antifungal activity of sunflower (Helianthus) species growing in North Alabama. Appl. Sci. 2019, 9, 3179. [CrossRef]

48. Chen, J.; Shen, Y.; Chen, C.; Wan, C. Inhibition of key citrus postharvest fungal strains by plant extracts in vitro and in vivo: A review. Plants 2019, 8, 26. [CrossRef] [PubMed]

49. Wan, C.; Shen, Y.; Nisar, M.F.; Qi, W.; Chen, C.; Chen, J. The antifungal potential of carvacrol against Penicillium digitatum through ${ }^{1} \mathrm{H}-\mathrm{NMR}$ based metabolomics approach. Appl. Sci. 2019, 9, 2240. [CrossRef]

50. De León, L.; Beltrán, B.; Moujir, L. Antimicrobial activity of 6-oxophenolic triterpenoids. Mode of action against Bacillus subtilis. Planta Med. 2005, 71,313-319. [CrossRef] [PubMed]

51. De León, L.; Moujir, L. Activity and mechanism of the action of zeylasterone against Bacillus subtilis. J. Appl. Microbiol. 2008, 104, 1266-1274. [CrossRef] [PubMed]

52. López, M.R.; de León, L.; Moujir, L. Antibacterial properties of phenolic triterpenoids against Staphylococcus epidermidis. Planta Med. 2011, 77, 726-729. [CrossRef] [PubMed]

53. Moujir, L.; López, M.R.; Reyes, C.P.; Jiménez, I.A.; Bazzocchi, I.L. Structural requirements for antimicrobial activity of phenolic nor-triterpenes from Celastraceae species. Appl. Sci. 2019, 9, 2957. [CrossRef]

54. Zhou, Y.X.; Xin, H.L.; Rahman, K.; Wang, S.J.; Peng, C.; Zhang, H. Portulaca oleracea L.: A review of phytochemistry and pharmacological effects. BioMed. Res. Int. 2015, 2015, 925631. [CrossRef] [PubMed]

55. Silva, R.; Carvalho, I.S. In vitro antioxidant activity, phenolic compounds and protective effect against DNA damage provided by leaves, stems and flowers of Portulaca oleracea (Purslane). Nat. Prod. Commun. 2014, 9, 45-50. [CrossRef]

56. Ahangarpour, A.; Lamoochi, Z.; Moghaddam, H.F.; Mansouri, S.M.T. Effects of Portulaca oleracea ethanolic extract on reproductive system of aging female mice. Int. J. Reprod. Biomed. 2016, 14, 205-212. Available online: http://journals.ssu.ac.ir/ijrmnew/article-1-730-en.html (accessed on 2 June 2020). [CrossRef]

57. Yoon, J.A.; Lim, C.; Cha, D.S.; Han, Y.T. Synthesis and evaluation of the lifespan-extension properties of oleracones D-F, antioxidative flavonoids from Portulaca oleracea L. Appl. Sci. 2019, 9, 4014. [CrossRef]

58. Tungmunnithum, D.; Elamrani, A.; Abid, M.; Drouet, S.; Kiani, R.; Garros, L.; Kabra, A.; Addi, M.; Hanno, C. A quick, green and simple ultrasound-assisted extraction for the valorization of antioxidant phenolic acids from Moroccan almond cold-pressed oil residues. Appl. Sci. 2020, 10, 3313. [CrossRef]

59. Zhao, W.; Yuan, Y.; Zhao, H.; Han, Y.; Chen, X. Aqueous extract of Salvia miltiorrhiza Bunge-Radix Puerariae herb pair ameliorates diabetic vascular injury by inhibiting oxidative stress in streptozotocin-induced diabetic rats. Food Chem. Toxicol. 2019, 129, 97-107. [CrossRef] [PubMed]

60. Zhang, L.J.; Chen, L.; Lu, Y.; Wu, J.M.; Xu, B.; Sun, Z.G.; Zheng, S.Z.; Wang, A.Y. Danshensu has anti-tumor activity in B16F10 melanoma by inhibiting angiogenesis and tumor cell invasion. Eur. J. Pharmacol. 2010, 643, 195-201. [CrossRef] [PubMed]

61. Kang, B.; Lee, S.; Seo, C.-S.; Kang, K.S.; Choi, Y.-K. Analysis and identification of active compounds from Salviae miltiorrhizae radix toxic to HCT-116 human colon cancer cells. Appl. Sci. 2020, 10, 1304. [CrossRef]

62. Haggar, F.A.; Boushey, R.P. Colorectal cancer epidemiology: Incidence, mortality, survival, and risk factors. Clin. Colon Rectal Surger. 2009, 22, 191-197. [CrossRef] [PubMed]

63. Mahapatra, D.K.; Asati, V.; Bharti, S.K. An updated patent review of therapeutic applications of chalcone derivatives (2014-present). Expert Opin. Ther. Pat. 2019, 29, 385-406. [CrossRef] [PubMed]

64. Zhuang, C.; Zhang, W.; Sheng, C.; Zhang, W.; Xing, C.; Miao, Z. Chalcone: A privileged structure in medicinal chemistry. Chem. Rev. 2017, 117, 7762-7810. [CrossRef] [PubMed]

65. Gomes, M.N.; Muratov, E.N.; Pereira, M.; Peixoto, J.C.; Rosseto, L.P.; Cravo, P.V.L.; Andrade, C.H.; Neves, B.J. Chalcone derivatives: Promising starting points for drug design. Molecules 2017, 22, 1210. [CrossRef] [PubMed]

66. Farooq, S.; Ngaini, Z. Recent synthetic methodologies for chalcone synthesis (2013-2018). Curr. Organocatalysis 2019, 6, 184-192. [CrossRef]

67. Rosa, G.P.; Seca, A.M.L.; Barreto, M.C.; Silva, A.M.S.; Pinto, D.C.G.A. Chalcones and flavanones bearing hydroxyl and/or methoxyl groups: Synthesis and biological assessments. Appl. Sci. 2019, 9, 2846. [CrossRef] 
68. Numonov, S.; Sharopov, F.S.; Atolikhshoeva, S.; Safomuddin, A.; Bakri, M.; Setzer, W.N.; Musoev, A.; Sharofova, M.; Habasi, M.; Aisa, H.A. Volatile secondary metabolites with potent antidiabetic activity from the roots of Prangos pabularia Lindl.-Computational and experimental investigations. Appl. Sci. 2019, 9, 2362. [CrossRef]

69. Pasupuleti, V.R.; Sammugam, L.; Ramesh, N.; Gan, S.H. Honey, propolis, and royal jelly: A comprehensive review of their biological actions and health benefits. Oxid. Med. Cell Longev. 2017, 2017, 1259510. [CrossRef] [PubMed]

70. Braakhuis, A. Evidence on the health benefits of supplemental propolis. Nutrients 2019, 11, 2705. [CrossRef] [PubMed]

71. Liu, J.R.; Ye, Y.L.; Lin, T.Y.; Wang, Y.W.; Peng, C.C. Effect of floral sources on the antioxidant, antimicrobial, and anti-inflammatory activities of honeys in Taiwan. Food Chem. 2013, 139, 938-943. [CrossRef] [PubMed]

72. Afonso, A.M.; Gonçalves, J.; Luís, Â.; Gallardo, E.; Duarte, A.P. Evaluation of the in vitro wound-healing activity and phytochemical characterization of propolis and honey. Appl. Sci. 2020, 10, 1845. [CrossRef]

73. Moujir, L.; Callies, O.; Sousa, P.M.C.; Sharopov, F.; Seca, A.M.L. Applications of sesquiterpene lactones: A review of some potential success cases. Appl. Sci. 2020, 10, 3001. [CrossRef]

74. Nadeem, M.; Imran, M.; Aslam Gondal, T.; Imran, A.; Shahbaz, M.; Muhammad Amir, R.; Wasim Sajid, M.; Batool Qaisrani, T.; Atif, M.; Hussain, G.; et al. Therapeutic potential of rosmarinic acid: A comprehensive review. Appl. Sci. 2019, 9, 3139. [CrossRef]

(C) 2020 by the authors. Licensee MDPI, Basel, Switzerland. This article is an open access article distributed under the terms and conditions of the Creative Commons Attribution (CC BY) license (http://creativecommons.org/licenses/by/4.0/). 